\title{
Secondary plant products against Culex pipiens (Linn.), with reference to some changes detected by scanning electron microscope
}

\author{
Khalid Osman', Ahmed AL-Emam ${ }^{2,3}$ and Mahmoud Moustafa ${ }^{4,5^{*}}$
}

\begin{abstract}
To find environment-friendly and low pest resistance natural mosquitocide, the bio-effects of smokes and oils obtained from leaves of Eucalyptus globulus and Ocimum basilicum against Culex pipiens (Linn.) were investigated. An influence of smokes and oils was tested on the loss ratio of eggs, larvae, pupae, and adult mortality of 1st and 2nd generations of Culex pipiens. Morphological changes of the 2 nd generation, including antennae and mouthparts of larvae and adults, were examined by using the scanning electron microscopy (SEM). The smokes of $O$. basilicum and $E$. globulus reduced the ratio value of the insect, especially the eggs' number and adults significantly within 2 generations that lasted 82 days. The impact of $O$. basilicum smokes on the larval molting and mortality rate was 83.15 and $95.05 \%$, respectively, compared to 29.85 and $82.43 \%$ for E. globulus. The lethal effect of O. basilicum smoke on adults had a loss rate of $100 \%$ in both generations than $75.86 \%$ by E. globulus. Essential oils from $O$. basilicum and E. globulus showed a severe and rapid killing effect of $C$. pipiens within 8 days with a loss ratio of 99.47 and $81.38 \%$ of larvae from eggs, respectively. Scanning electron microscopy showed that both smokes could cause prominent malformation to the larval antennae, siphon, and adult mouthparts. In conclusion, either E. globulus or O. basilicum smokes in the long term or either of their oils in the short term could be used as natural repellent agents against Culex pipiens.
\end{abstract}

Keywords: Culex pipiens, Secondary metabolites, Eucalyptus, Ocicum, Essential oils, Scanning electron microscopy

\section{Background}

Plant natural products have been historically used in many parts of the world to repel and kill mosquitoes. Many plant species had been screened for their mosquito repellent and insecticide property (Shaalan et al., 2005; Ghosh et al., 2012; Ravindran et al., 2012). Repellent activities and their effects on the mosquitoes were reported for Eucalyptus maculate against Anopheles gambiae and Anopheles funestus (Trigg, 1996);

\footnotetext{
*Correspondence: mfmostfa@kku.edu.sa

${ }^{4}$ Department of Biology, Faculty of Science, King Khalid University, Abha 61413, Saudi Arabia

${ }^{5}$ Department of Botany, Faculty of Science, South Valley University, Qena, Egypt

Full list of author information is available at the end of the article
}

Ocicum selloi against Anopheles braziliensis (Paula et al., 2003); neem plant extract against Aedes, Culex, Anopheles (Sharma et al., 1993; Dua and Sharma, 1995); and $O$. mericanum against Anopheles dirus, Aedes aegypti, and Culex quinquefasciatus (Tawatsin et al., 2001). The action of smoke from smoldering mosquito coils against Aedes aegypti, Anopheles stephensi, and Culex pipiens fatigans were studied by Chadwick (1975). Mosquito coil prepared from Mesue ferra leaf powder was investigated for its smoke effect against $C x$. quiquefasciatus adults (Singha et al., 2011). They concluded that the smoke from M. ferra could play a crucial role in the pause of transmission of many diseases, whereas the mosquitoes act as vector at the individual level. Smoke toxicity test 
of Ocimum canum against Cx. quinquefasciatus, Anopheles stephensi, and Ae. aegypti was tested by Ramkumar et al. (2015) who found that smoke of the leaf powder could be used as an efficient toxicity agent against many species of mosquitoes.

Murugan et al. (2016) reported that $O$. canum leaf extract and powder have toxicity effects on $C x$. quinquefasciatus, Ae. aegypti, and An. stephinsi adults. Furthermore, Asiamah and Botchey (2019) stated that there were repellent and mosquitocidal properties of smoke from oil and the non-polar extracts of $O$. viride leaf against Ae. aegyptii.

Essential oils from plants play a major role in protecting plants from pests (Isman and Machial 2006; Bakkali et al., 2008). On the other hand, Sujatha et al. (1988) found that Acorus calamus extract induced malformations to An. stephensi, Cx. quinquefasciatus, Ae. aegypti, Madhuca longifolia, and Cx. quinquefasciatus.

The present study aimed to evaluate the effect of the smokes and oils from E. globulus and O. basilicum on morphological malformation and biological behavioral activities of the mosquito species, $C x$. pipiens.

\section{Materials and methods Insects rearing}

Culex pipiens egg batches were obtained in year 2019 from the laboratory of Zoology Department, Faculty of Science, South Valley University (SVU), Egypt. The insects were reared in glass cages $(50 \mathrm{~mm}$ in diameter and $100 \mathrm{~mm}$ high) with a little bit of bread crumbs and covered with cloth. Every day, water and bread crumbs of all jars were removed in order to maintain a population of young larvae (1st, 2nd, 3rd, and 4th instars) ready to be used in the experiments. The treatments were kept under the laboratory conditions of $25 \pm 5^{\circ} \mathrm{C}, 25 \pm 10 \%(\mathrm{RH})$, and a photoperiod of $16 \mathrm{~h}$ of light and $8 \mathrm{~h}$ of darkness.

\section{Bioassay tests \\ Effect of Eucalyptus globulus and Ocimum basilicum smokes on Cx. pipiens}

This experiment was conducted to determine the dosedependent toxicity smokes of Eucalyptus globulus and Ocimum basilicum against different stages of $C x$. pipiens. Exposing such stages to the tested smokes was conducted daily by burning 10 dried grams of the leaves from each plant. Smoking process was continued for about $15 \mathrm{~min}$ for each plant in 4 rooms (length $5.40 \mathrm{~m}$, width $2.15 \mathrm{~m}$, and height $3 \mathrm{~m}$ ). After treatments, daily monitoring was carried out for 82 days (two generations of the insect) for each dose of smokes, to estimate the mortality rate of $C x$. pipiens larvae and adults by picking and separating the dead individuals.
Effect of the essential oils of O. basilicum and E. globulus on $\mathrm{Cx}$. pipiens

O. basilicum and E. globulus essential oils were purchased from the Captain Company accredited and registered to the Ministry of Health No. 2978/2002, Qena (Upper Egypt). For the treatments' application, the total volume used in each spray was $1 \mathrm{ml}$, applied on glass flasks $(50 \mathrm{~mm}$ in diameter and $100 \mathrm{~mm}$ high) layered with a sterilized filter paper, to be sure that the treatments were retained, at $40 \mathrm{kPa}$. Three doses $(6,12$, and 241/Petri dish) of O. basilicum and E. globulus were sprayed and 3 replicates were done. A treatment without essential oils was used as a control. After the application of treatments, daily monitoring, by separating and counting the dead larvae individuals, was carried out during the following 8 days after the application of each dose of essential oil.

\section{Scanning electron microscope (SEM)}

Chaudhary and Gupta (2004) protocol for SEM studies, was followed. Egg batches were collected from water drains by taking surface water included egg batches with a small bucket. The developed larvae out of the collected eggs were stored remaining in $70 \%$ ethanol, besides, some continued to be reared in the laboratory. The specific identification was made from the reared adult mosquitoes. For SEM studies, both larvae and adults were passed through the essential dry point and placed on SEM stubs with only a thin double-sided adhesive tape strip (Kirti and Kaur, 2011). Under the smokes of E. globulus and $O$. basilicum, larvae and adults of $C x$. pipiens were scanned by JSM- 6100 SEM. The effects on the larval antennae and siphons and adult antennae and mouthparts were investigated.

\section{Statistical analysis}

Data were analyzed by SPSS program using one-way analysis of variance (ANOVA). Mean differences were compared using multiple comparison range test by Excel program for three replicates

\section{Results and discussion}

The effect of the smoke was continued for 2 generations (82 days), intervals of 15 min smoke every day. Extracted oils from E. globulus and O. basilicum had been investigated for their effect on the biological behavioral activities of $C x$. pipiens. The data recorded about the eggs, alive larvae, larval molting, larval mortality, alive pupae, alive adults, and adult mortality of $C x$. pipiens under the effect of E. globulus smoke and in control treatment conditions are presented in Table 1 . It was found that in the 1st generation, the $C x$. pipiens under normal conditions showed very low of loss rates in all stages, while in the 2nd generation, it was found only one adult had 
Table 1 Culex pipiens individual numbers under the effect of smokes of Eucalyptus globulus and Ocimum basilicum leaves for two generations

\begin{tabular}{|c|c|c|c|c|c|c|c|c|}
\hline Treatment & Generation & Eggs & Alive larvae & Larval molting & Larval mortality & Pupal no. & Alive adults & Adult mortality \\
\hline \multirow[t]{6}{*}{ Control } & $1 s t$ & $\begin{array}{l}7.05 \\
(289.0)\end{array}$ & $\begin{array}{l}7.09 \\
(289 \pm 9.61)\end{array}$ & $\begin{array}{l}6.020 \\
(247 \pm 2.46)\end{array}$ & $\begin{array}{l}0.51 \\
(21 \pm 0.44)\end{array}$ & $\begin{array}{l}5.51 \\
(226 \pm 2.16)\end{array}$ & $\begin{array}{l}5.51 \\
(226 \pm 2.46)\end{array}$ & 0.00 \\
\hline & Loss\% & & $0.00 \%$ & $14.53 \%$ & $8.500 \%$ & $000.00 \%$ & $0.00 \%$ & $0.00 \%$ \\
\hline & 2nd & $\begin{array}{l}6.80 \\
(279.0)\end{array}$ & $\begin{array}{l}6.44 \\
(264 \pm 10.41)\end{array}$ & $\begin{array}{l}5.51 \\
(226 \pm 3.21)\end{array}$ & $\begin{array}{l}0.46 \\
(19.0 \pm 0.75)\end{array}$ & $\begin{array}{l}5.050 \\
(207 \pm 3.00)\end{array}$ & $\begin{array}{l}5.05 \\
(207 \pm 3.21)\end{array}$ & $\begin{array}{l}1.00 \\
(41.0 \pm 1.00)\end{array}$ \\
\hline & Loss\% & & $11.83 \%$ & $14.39 \%$ & $8.41 \%$ & $8.41 \%$ & $0.00 \%$ & 19.81 \\
\hline & Df & 10.0 & 25.0 & 21.0 & 2.00 & 21.0 & 21.0 & 41.0 \\
\hline & $1 \mathrm{st} / 2 \mathrm{nd}$ & $3.46 \%$ & $8.65 \%$ & $8.50 \%$ & $8.46 \%$ & $8.40 \%$ & $8.40 \%$ & $9.47 \%$ \\
\hline \multirow[t]{6}{*}{ E. globulus } & $1 s t$ & $\begin{array}{l}19.67 \\
(810)\end{array}$ & $\begin{array}{l}6.02 \\
(726 \pm 8.74)\end{array}$ & $\begin{array}{l}3.27 \\
(134 \pm 1.21)\end{array}$ & $\begin{array}{l}14.44 \\
(592 \pm 18.13)\end{array}$ & $\begin{array}{l}3.27 \\
(134 \pm 1.21)\end{array}$ & $\begin{array}{l}3.27 \\
(134 \pm 1.21)\end{array}$ & $\begin{array}{l}2.24 \\
(92 \pm 4.00)\end{array}$ \\
\hline & Loss\% & & $10.37 \%$ & $81.54 \%$ & $81.51 \%$ & $77.36 \%$ & $0.00 \%$ & 68.66 \\
\hline & $2^{\text {nd }}$ & $\begin{array}{l}4.49 \\
(184.0)\end{array}$ & $\begin{array}{l}3.51 \\
\left(144 \pm 5.44^{* *}\right)\end{array}$ & $\begin{array}{l}0.98 \\
\left(40 \pm 0.60^{* *}\right)\end{array}$ & $\begin{array}{l}2.54 \\
\left(104 \pm 3.14^{* *}\right)\end{array}$ & $\begin{array}{l}0.98 \\
(40.0 \pm 0.60)\end{array}$ & $\begin{array}{l}0.98 \\
(40.0 \pm 0.60)\end{array}$ & $\begin{array}{l}0.98 \\
\left(40 \pm 0.60^{* *}\right)\end{array}$ \\
\hline & Loss\% & & $21.74 \%$ & $72.23 \%$ & $72.23 \%$ & $72.23 \%$ & $0.00 \%$ & $100 \%$ \\
\hline & Df & 626.0 & 582.0 & 94.00 & 488.0 & 94.00 & 94.00 & 52.00 \\
\hline & 1st/2nd & $77.28 \%$ & $80.17 \%$ & $29.85 \%$ & $82.43 \%$ & $29.85 \%$ & $29.85 \%$ & $75.86 \%$ \\
\hline \multirow[t]{6}{*}{ O. basilicum } & $1 s t$ & $\begin{array}{l}11.66 \\
(478)\end{array}$ & $\begin{array}{l}11.39 \\
(467 \pm 15.27)\end{array}$ & $\begin{array}{l}0.56 \\
(23 \pm 0.58)\end{array}$ & $\begin{array}{l}10.83 \\
(444 \pm 11.0)\end{array}$ & $\begin{array}{l}00.56 \\
(23 \pm 0.58)\end{array}$ & $\begin{array}{l}00.56 \\
(23 \pm 0.58)\end{array}$ & $\begin{array}{l}00.56 \\
(23 \pm 0.58)\end{array}$ \\
\hline & Loss\% & & $2.31 \%$ & $95.08 \%$ & $95.08 \%$ & $0.00 \%$ & $0.00 \%$ & $100 \%$ \\
\hline & 2nd & $\begin{array}{l}5.51 \\
(22.06)\end{array}$ & $\begin{array}{l}2.22 \\
\left(91.0 \pm 4.18^{* *}\right)\end{array}$ & $\begin{array}{l}1.68 \\
(69.0 \pm 0.93)\end{array}$ & $\begin{array}{l}0.54 \\
(22.0 \pm 0.60)\end{array}$ & $\begin{array}{l}1.68 \\
\left(69.0 \pm 0.93^{*}\right)\end{array}$ & $\begin{array}{l}1.68 \\
\left(69.0 \pm 0.93^{*}\right)\end{array}$ & $\begin{array}{l}1.68 \\
(69.0 \pm 0.93)\end{array}$ \\
\hline & Loss\% & & $59.73 \%$ & $24.18 \%$ & $31.88 \%$ & $0.00 \%$ & $0.00 \%$ & $100 \%$ \\
\hline & Df & 252.0 & 376 & 46.0 & 422 & 46.0 & 46.0 & 46.0 \\
\hline & 1st/2nd & $52.72 \%$ & $80.51 \%$ & $83.15 \%$ & $95.05 \%$ & $0.00 \%$ & $0.00 \%$ & $100 \%$ \\
\hline
\end{tabular}

Df, difference in the numbers between each stage of two generations; number of individuals of each stage between brackets \pm SD of three replicates

${ }^{* *} p$ value significant $(<0.01)$

been lost represented (9.47\%). It showed also the lowest loss rate $(3.46 \%)$ in eggs, and it ranged between 8.40 and $8.65 \%$ in alive larvae, larval molting, larval mortality, alive pupae, and alive adults.

\section{Effect of E. globulus and O. bacilicum smokes on CX. pipiens}

As shown in Table 1, the effect of E. globulus smoke on the first generation of $C x$. pipiens exhibited loss rates of $81.5,81.51$, and $77.36 \%$ for larval molting, larval mortality, and pupal individual number, respectively. No loss was recorded in the alive adults whereas mortality of the adults showed loss rates of $68.66 \%$ under E. globulus smoke. On the second generation, the impact of $E$. globulus smoke had a loss ratio on the larval molting, larval mortality, and pupal individual number by $72.23 \%$ and for adult mortality by $100 \%$. In contrast, alive adults of $C x$. pipiens from pupae showed no loss at all. The effect of E. globulus smoke on all stages of $C x$. pipiens upon the two generations is shown in Table 1. E. globulus smoke severely affected all stages of $C x$. pipiens, whereas the highest mortality rate was found in larva by $82.43 \%$.
E. globulus smoke equally affected larval molting, alive adults, and alive pupa by $29.85 \%$. The loss rate in the eggs, alive larvae, and adult $C x$. pipiens were found to be in the range between 77.28 and $80.17 \%$. O. basilicum smoke affected the first generation of $C x$. pipiens by a loss rate of $95.08 \%$ for larval molting and mortality and $100 \%$ for adult mortality. In contrast, no changes were observed in the hatched pupal and alive adults under $O$. basilicum smoke. The second generation of $C x$. pipiens had been affected by $59.73 \%$ for alive larvae, by $24.18 \%$ for larval molting, and by $31.88 \%$ for larval mortality, whereas the adults had a loss ratio of $100 \%$. Upon the two generations, it showed a sever effect on eggs, alive larvae, larval mortality, molting, and adult mortality whereas the highest mortality rate found to be in larva and adults by 95.05 and $100 \%$, respectively. In contrast, $O$. basilicum smoke did not show any effect on the alive pupal stage. The differences between 2 nd and 1st generations of hatched eggs under no smokes were found to be $3.46 \%$ less than those subjected to the smokes of $E$. globulus (77.28\%) and O. basilicum (52.72) (Figs. 1 and 2 ; Table 1) which proved the toxic effect of both smokes 

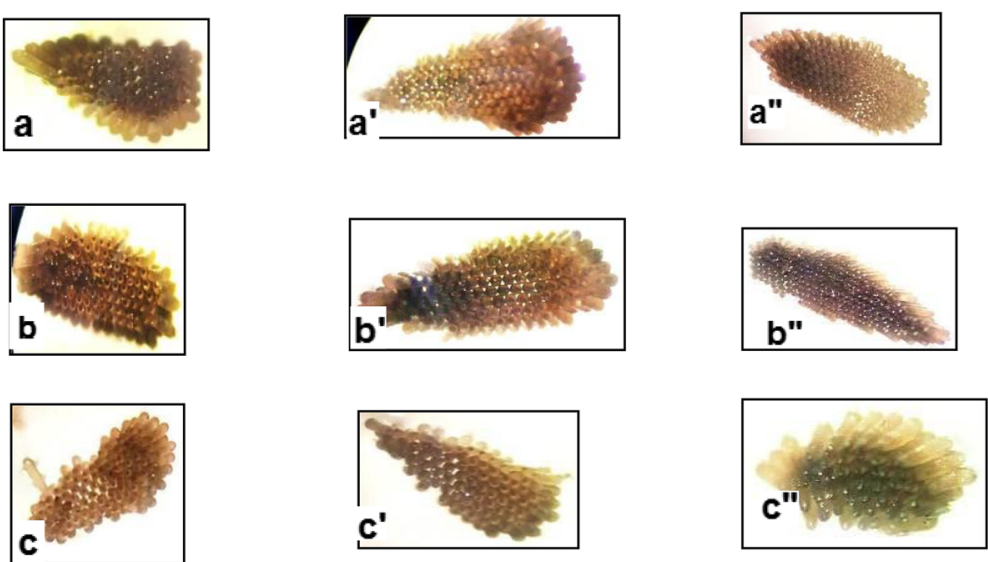

Fig. 1 Culex pipiens egg numbers under no smoke ( $\mathbf{a}, \mathbf{b}$, and $\mathbf{c})$, smokes of Ocimum basilicum (a', b', and $\left.\mathbf{c}^{\prime}\right)$, and smokes of Eucalyptus globulus $\left(\mathbf{a} ", \mathbf{b} "\right.$, and $\left.\mathbf{c}^{\prime \prime}\right)$ of the first culicid generation using light microscopy

generated from E. globulus and O. basilicum. The differences between E. globulus smoke and O. basilicum smoke are probably due to the oily layer from the smoke of E. globulus covering the container surface.

These findings are in agreement with the other researches that showed that the smoke possesses toxicity to various pests. As plant products contain multiple chemical constituents, smoke burning from it also contains some of those active principles. Several plant smokes showed a toxic effect against mosquitoes. For example, smoke from Albizza amara reported to have a more toxic effect on Ae. aegypti than O. bascilicum smoke (Murugan et al., 2007). It was reported that smokes of Ficus krishnae had a toxic efficacy against
Anopheles stephensi Liston and Cx. vishnui group of mosquitoes (Haldar et al., 2014). The smoke obtained from various solvent extracts from Lantana camara leaves showed different levels of repellence against female anopheles mosquitos (Akumu et al., 2014). Volatiles found in the smoke resulted either from burning or from fresh leaves of Corymbia citriodora and Ocimum suave and showed remarkable repellent activities against host-seeking Ae. aegypti and An. arabiensis mosquitoes (Dube et al., 2011).

Obtained results showed that the complete mortality of adults of $C x$. pipiens was observed by $E$. globulus smoke treatment under room conditions during the 2nd generation. Moreover, the current results showed the
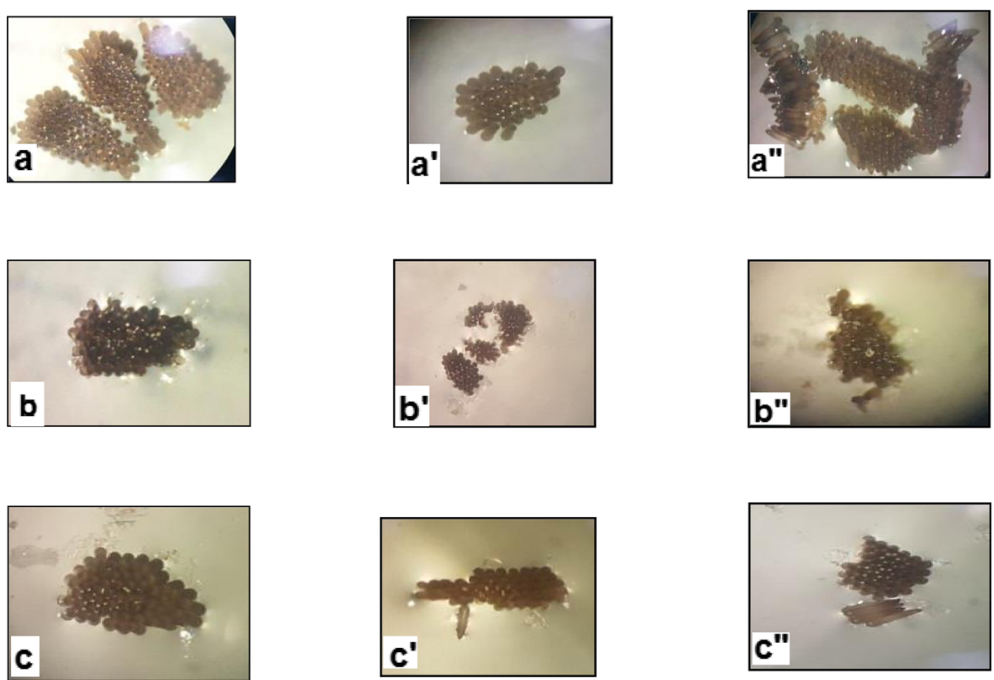

Fig. 2 Culex pipiens eggs numbers under no smoke (a, b, and c), smokes of Ocimum basilicum (a', b', $\mathbf{c}^{\prime}$, and $\left.\mathbf{d}^{\prime}\right)$, and smokes of Eucalyptus globulus (a", b", and $\left.\mathbf{c}^{\prime \prime}\right)$ of the second culicid generation using light microscopy 
Table 2 Culex pipiens individual numbers under the effect of oils of Eucalyptus globulus and Ocimum basilicum for eight days

\begin{tabular}{llllll}
\hline Treatment & Generation & Eggs & Alive larvae & Larval molting & Larval mortality \\
\hline Control & 1st & $32.63(261)$ & $32.63(200 \pm 70.71)$ & $25\left(200 \pm 2.46^{*}\right)$ & $7.63\left(61 \pm 2.46^{*}\right)$ \\
& Loss\% & & $2.338 \%$ & & \\
E. globulus & 1 st & $19.67(190)$ & $0.125(1 \pm 0.92)$ & $0.125\left(1.00 \pm 1.21^{* *}\right)$ & $14.44\left(189 \pm 1.77^{*}\right)$ \\
& Loss\% & & $99.47 \%$ & & \\
O. basilicum & 1 st & $13.88(111)$ & $18.92(21.0 \pm 5.04)$ & & $81.08(21.0 \pm 4.59)$ \\
& Loss\% & & $81.38 \%$ & & \\
& & & &
\end{tabular}

Number of individuals of each stage between brackets \pm SD of three replicates

${ }^{*} p$ value significant $(<0.05)$

** $p$ value significant $(<0.01)$

severe mortality appeared only after 82 days of continuous smoking. Thus, it could be interpreted that we smoked the Cx. pipiens in few minutes and other researchers smoked very heavily in closed areas. Furthermore, the present results found that the toxicity efficacy between smokes of E. globulus and O. basilicum either for the 1st or 2nd generations varied greatly, as for example that there was an increase in the loss rate of larval molting and larval mortality under $O$. basilicum smoke than that of E. globules. However, the loss rate in the number of egg production and adult mortality caused by E. globulus was higher than that caused by smoke of $O$. basilicum and could be due to the nature of the chemicals present in each plant (Brooker and Kleinig, 2006). 1, 8-Cineole has been reported to be the most important chemical in the genus of Eucalyptus and is largely attributed to various pesticide characteristics (Duke, 2004). On the other hand, O. basilicum essential oil was mainly composed of aromatic ether estragol (74.0\%) and the terpene with alcohol group linalool (17.8\%), which is known to be a repellent and had toxic activities against insect species (Regnault-Roger et al., 1993).

The current results could be due to the layer thickness of oils covering the water surface. Meanwhile, these larvae breathe by their syphon of the terminal body end. Moreover, the number of released larvae of E. globulus was fewer than that was treated by $O$. basilicum, and this may be due to the thickness of the E. globulus oil that was more than that of the O. basilicum oil.

\section{Effect of the essential oils on $C x$. pipiens}

According to Table 2, the results showed an acute effect on hatched eggs for those treated by oils of E. globulus and $O$. bacilicum than the control across 8 days. In the case of control, the loss ratio of larvae resulted from hatched egg was $2.338 \%$ and those treated by oils of $O$. basilicum and E. globulus were $81.38 \%$ and $99.47 \%$, respectively. Again, this support that both smokes from

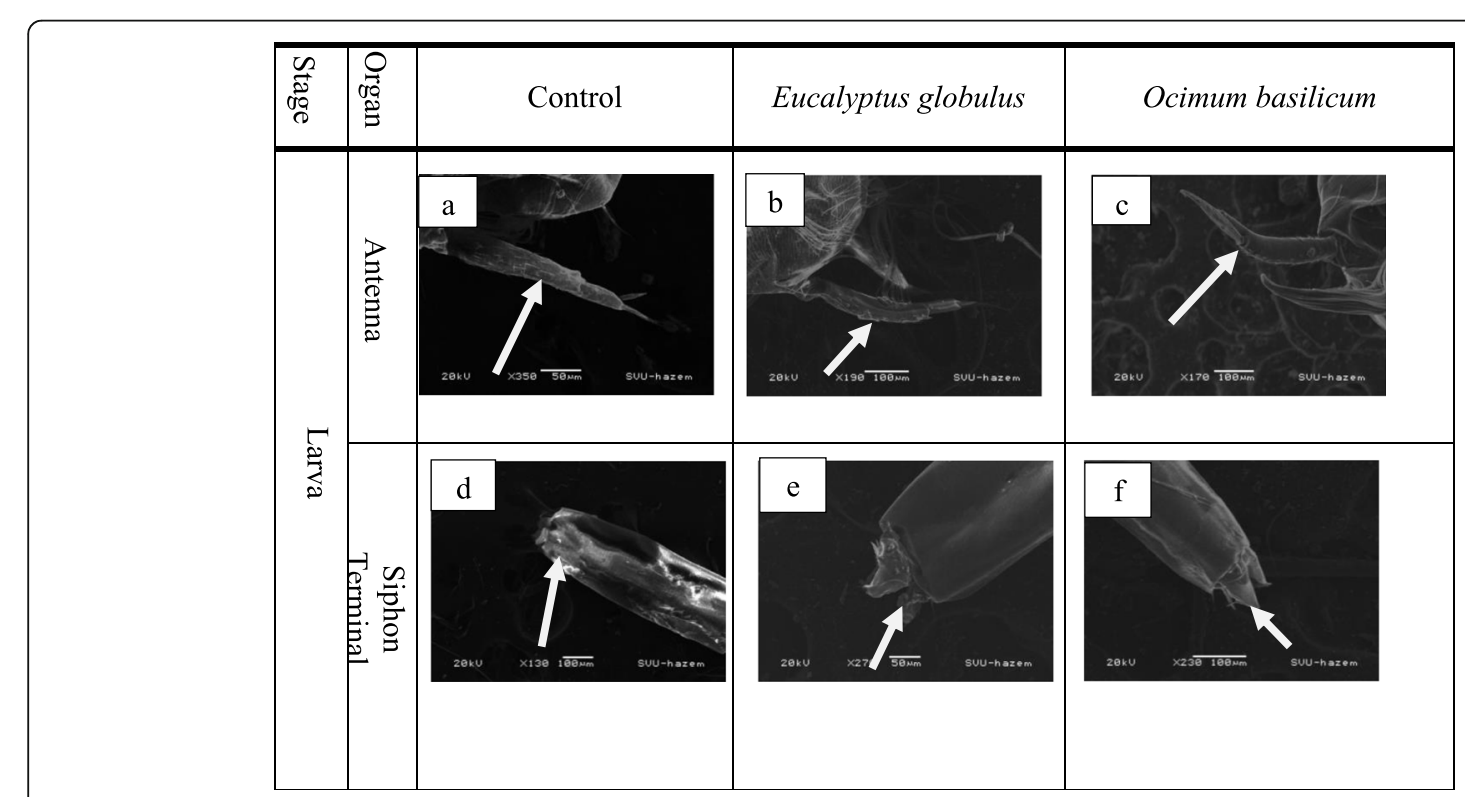

Fig. 3 Scanning electron microscopic (SEM) of the larval antennae and siphons of Culex pipiens under no smoke, smoke of Eucalyptus globulus, and smoke of Ocimum basilicum 


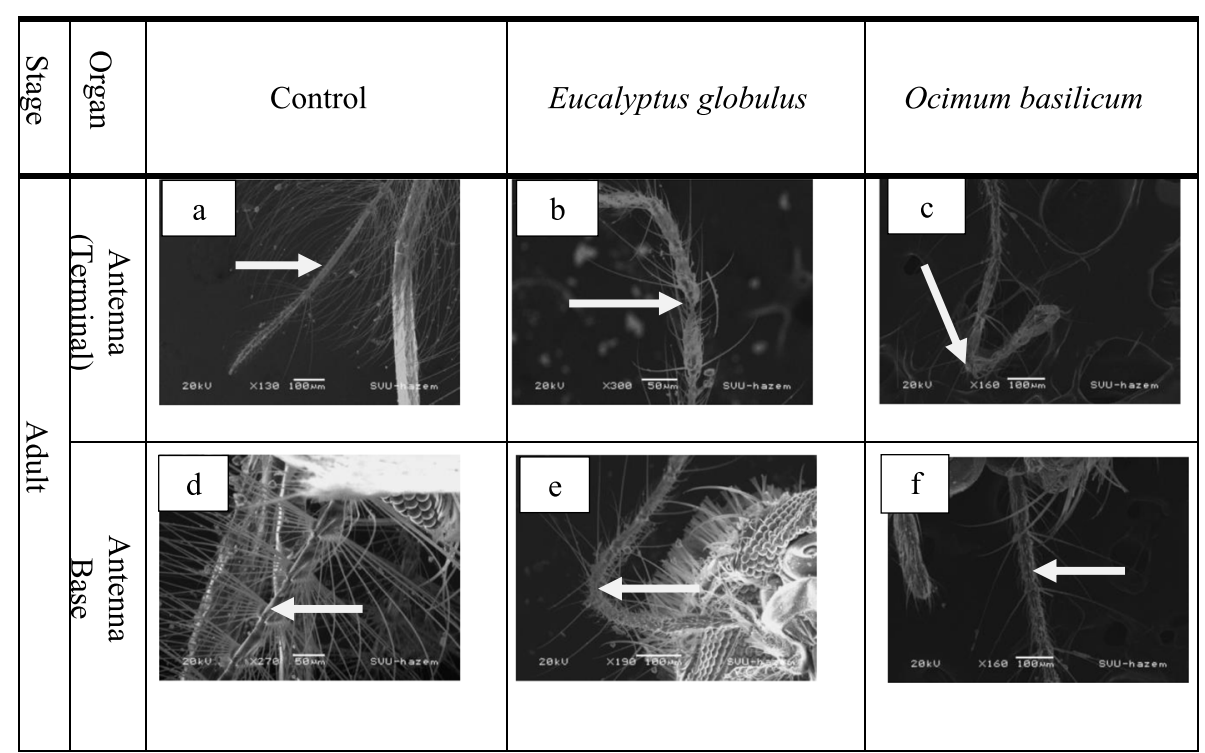

Fig. 4 Scanning electron microscopic (SEM) of adult antennae and mouth parts of Culex pipiens under no smoke and smoke of Eucalyptus globulus and smoke of Ocimum basilicum

leaves of E. globulus and O. bacilicum had a toxic effect probably due to specific toxic chemicals against $C x$. pipiens. It was found that E. globulus oil possesses a wide spectrum of biological activity including anti-insecticidal repellent (Batish et al., 2008). Previous researches showed that oils of many plants had various activities against eggs hatching, adults, developmental traits, and larva/pupa susceptibilities (Regnault-Roger and Hamraoui, 1994; Papachristos and Stamopoulos, 2002).

\section{SEM observations}

SEM of the larval antennae, siphons, adult antennae, and mouth parts of $C x$. pipiens subjected to the E. globulus and $O$. basilicum smokes were found to be morphologically abnormal compared to control (Figs. 3 and 4). It was evident that the bending of $C x$. pipiens under E. globulus smoke (Fig. $3 \mathrm{~b}$ ) was more than that $O$. basilicum smoke (Fig. 3c). Also, the number of sensory hairs on the larval antennae of non-exposed $C x$. pipiens to smoke was more than those exposed to E. globulus and O. basilicum smokes. The variation in the number of sensory hairs is probably due to the oily layer formed from E. globulus and $O$. basilicum smokes and why larvae underwent abnormal growth with little bed sensory hairs. As shown in Fig. 3d, there are no active processes in the terminal ends of the siphon of the control sample, while complete active processes in the siphons were observed under smokes of E. globulus and O. basilicum (Fig. 3e, f). Also, it was observed that there was abnormal growth of the antenna as there was a cut in some segments under $E$. globulus smoke (Fig. 4b) and prominent curvature under the effect of both smokes of O. basilicum and E. globulus
(Fig. 4e). A curvature in the antennae may be a result from an increasing surface area provided with more sensory hairs and plates to have a benefit from any amount of oxygen that is contaminated by smokes. These results were confirmed by Sujatha et al. (1988) who estimated the effect of Acorus calamus extract on Cx. quinquefasciatus and to $C x$. quinquefasciatus and found morphological malformations to the Culex spp.

\section{Conclusion}

Smokes and oils of E. globulus and O. basilicum leaves affected the life cycles of $C x$. pipiens with varying degrees of mortality rate. Therefore, both smokes and oils of E. globulus and O. basilicum can be applied as natural products against mosquitoes.

\section{Abbreviations}

ANOVA: Analysis of variance; Eos: Essential oils; PM: Post meridiem; $\mathrm{RH}$ : Relative humidity; SEM: Scanning electron microscope; SPSS: Statistical Package for the Social Sciences

\section{Acknowledgements}

We would like to thank the team of Entomology Lab., Faculty of Science, South Valley University (SVU), Egypt, for providing the original population of CX. pipiens egg batches.

\section{Authors' contributions}

$\mathrm{KO}$ and $\mathrm{MM}$ performed the idea of this article, achieved the laboratory performance, and wrote the manuscript. AA participated in writing the manuscript and mathematical analysis. The authors read and approved the final manuscript.

Funding

King Khalid University, Research Group Number (R.G.P.1/134/40). 


\section{Availability of data and materials}

All data of the study have been presented in the manuscript, and high quality and grade materials were used in this study.

\section{Ethics approval and consent to participate}

Not applicable.

\section{Consent for publication}

Not applicable.

\section{Competing interests}

The authors declare that they have no competing interests.

\section{Author details}

'Department of Zoology Faculty of Science, South Valley University, Qena, Egypt. ${ }^{2}$ Department of Pathology, College of Medicine, King Khalid University, Abha, Saudi Arabia. ${ }^{3}$ Department of Forensic Medicine and Clinical Toxicology, Faculty of Medicine, Mansoura University, Mansoura, Egypt. ${ }^{4}$ Department of Biology, Faculty of Science, King Khalid University, Abha 61413, Saudi Arabia. ${ }^{5}$ Department of Botany, Faculty of Science, South Valley University, Qena, Egypt.

Received: 22 November 2019 Accepted: 2 March 2020

Published online: 23 March 2020

\section{References}

Akumu E, Sellah K, Anthoney ST, Mutuku NC (2014) Repellency of Lantana camara leaves smoke against female Anopheles mosquitoes. Int J Bioassays 3(1):1695-1698

Asiamah EA, Botchey MH (2019) Repellent and mosquitocidal properties of smoke from oil and non-polar extracts of Ocimum viride Leaf Against Aedes aegyptii. J Appl Sci 19(6):618-623

Bakkali F, Averbeck S, Averbeck D, Idaomar M (2008) Biological effects of essential oils a review. Food Chem Toxicol 46:446-475

Batish DR, Singh HP, Kohli RK, Kaur S (2008) Eucalyptus essential oil as a natural pesticide. Forest Ecol Manag 256:2166-2174

Brooker MIH, Kleinig DA (2006) Field guide to Eucalyptus. vol:1. South-eastern Australia, Third edition. Bloomings, Melbourne

Chadwick PR (1975) The activity of some pyrethroids, DDT and lindane in smoke from coils for biting inhibition, knockdown and kill of mosquitoes (Diptera, Culicidae). Bull Entomol Res 65(1):97-107

Chaudhary S, Gupta S (2004) Scanning electron microscopic studies on the egg architecture of Anopheles (Cellia) stephensi Liston (Diptera: Culicidae). Proc Zool Soc (Calcutta) 57(1):1-4 compositions of essential oils from leaves of four eucalypts. Taiwan J For Sci 2:49-61

Dua VK, Nagpal BN, Sharma VP (1995) Repellent action of neem cream against mosquitoes. Indian J Malariol 32:47-53

Dube FF, Tadesse K, Birgersson G, Seyoum E, Tekie H, Ignell R, Hill SR (2011) Fresh, dried or smoked? repellent properties of volatiles emitted from ethnomedicinal plant leaves against malaria and yellow fever vectors in Ethiopia. Malar J. https://doi.org/10.1186/1475-2875-10-375

Duke, JA (2004) Dr. Dukes Phytochemical and Ethnobotanical databases. Available online at http://www.ars-grin.gov/duke/ (Accessed on 9 June 2008).

Ghosh A, Chowdhury N, Chandra G (2012) Plant extracts as potential mosquito larvicides. Indian J Med Sci 135:581-598

Haldar KM, Ghosh P, Chandra G (2014) Larvicidal, adulticidal, repellency and smoke toxic efficacy of Ficus krishnae against Anopheles stephensi Liston and Culex vishnui group mosquitoes. Asian Pac J Trop Dis. 4:S214-S220

Isman MB, Machial CM (2006) Pesticides based on plant essential oils: from traditional practice to commercialization. In: Rai M, Carpinella MC (eds). Naturally Occurring Bioactive Compounds pp: 29-44

Kirti JS, Kaur S (2011) Scanning Electron Microscopic studies on fourth instar larva and pupa of Culex quiquefasciatus Say (Diptera: Culicidae). Ann Entomol 29(1):9-14

Murugan JM, Ramkumar G, Shivakumar MS (2016) Insecticidal potencial of Ocimum canum plant extracts against Anopheles stephensi, Aedes aegypti and Culex quinquefasciatus larval and adult mosquitoes (Diptera: Culicidae). Nat Prod Res 30(30):1193-1196

Murugan K, Murugan P, Noortheen A (2007) Larvicidal and repellent potential of Albizzia amara Boivin and Ocimum basilicum Linn against dengue vector, Aedes aegypti (Insecta: Diptera: Culicidae). Bioresour Technol 98(1):198-201
Papachristos, DP and Stamopoulos DC (2002) Toxicity of vapours of three essential oils to the immature stages of Acanthoscelides obtectus (Say) (Coleoptera: Bruchidae). J Stored Prod Res 38 (4):365-373.

Paula JP, Carnerio MR, Pumgartten FJR (2003) Chemical compistion, toxicity and mosquito repellency of Ocimum selloi oil. J Ethnopharmacol 88:253-260

Ramkumar G1, Karthi S, Muthusamy R, Natarajan D and Shivakumar MS (2015) Adulticidal and smoke toxicity of Cipadessa baccifera (Roth) plant extracts against Anopheles stephensi, Aedes aegypti, and Culex quinquefasciatus. Parasitol Res 114(1):167-173

Ravindran J, Samuel T, Alex E, William J (2012) Adulticidal activity of Ageratum houstonianum Mill. (Asteraceae) leaf extracts against three vector mosquito species (Diptera: Culicidae). Asian Pac J Trop Biomed 2(3):177-179

Regnault-Roger C, Hamraoui A (1994) Inhibition of reproduction of Acanthoscelides obtectus Say (Coleoptera), a kidney bean (Phaseolus vulgaris) bruchid, by aro-matic essential oils. Crop Prot 13:624-628

Regnault-Roger C, Hamraoui A, Holeman M, Theron E, Pinel R (1993) Insecticidal effect of essential oils from mediterranean plants upon Acanthoscelides obtectus Say (Coleoptera: Bruchidae), a pest of kidney bean (Phaseolus vulgaris L.). J Chem Ecol 19:1233-1244

Shaalan EAS, Canyonb D, Younesc MWF, Wahaba HA, Mansoura AH (2005) A review of botanical phytochemicals with mosquitocidal potential. Environ Int 31:1149-1166

Sharma VP, Nagpal BN, Srivastava A (1993) Effectiveness of neem oil mats in repelling mosquitoes. Transactions of the Royal Society of Tropical Medicine and Hygiene. 87(6):626

Singha S, Adhikari U, Chandra G (2011) Smoke repellency and mosquito larvicidal potentiality of Mesue ferra L. leaf extract against filarial vector Culex quinquefasciatus Say. Asian Pac J Trop Biomed 1(1):S119-S123

Sujatha CHV, Vasuki TM, Kalyanasundaran M, Das PK (1988) Evaluation of plant extracts for biological activity against mosquitoes. Int Pest Control 30:122124

Tawatsin A, Wratten SD, Scott RR, Thavara U, Techadamrongsin Y (2001) Repellency of volatile oils from plants against three mosquito vectors. $J$ Vector Ecol 26(1):76-82

Trigg JK (1996) Evaluation of a Eucalyptus-based repellent against Anopheles species in Tanzania. J Am Mosquito Contr 12:243-246

\section{Publisher's Note}

Springer Nature remains neutral with regard to jurisdictional claims in published maps and institutional affiliations.

\section{Submit your manuscript to a SpringerOpen ${ }^{\circ}$ journal and benefit from:}

- Convenient online submission

- Rigorous peer review

- Open access: articles freely available online

High visibility within the field

- Retaining the copyright to your article

Submit your next manuscript at $\boldsymbol{\triangleright}$ springeropen.com 